Cipango Cahiers d'études japonaises

$21 \mid 2014$

Nouveaux regards sur les arts de la scène japonais II

\title{
In memoriam Jean-Jacques Tschudin
}

\section{Claire-Akiko Brisset}

\section{(2) OpenEdition \\ Journals}

\section{Édition électronique}

URL : https://journals.openedition.org/cipango/2153

DOI : 10.4000/cipango. 2153

ISSN : 2260-7706

\section{Éditeur}

INALCO

Édition imprimée

Date de publication : 31 décembre 2014

ISSN : 1164-5857

\section{Référence électronique}

Claire-Akiko Brisset, «In memoriam Jean-Jacques Tschudin », Cipango [En ligne], 21 | 2014, mis en ligne le 26 septembre 2016, consulté le 30 juin 2021. URL : http://journals.openedition.org/cipango/ 2153 ; DOI : https://doi.org/10.4000/cipango.2153

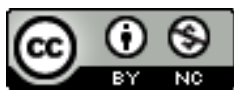

Cipango est mis à disposition selon les termes de la Licence Creative Commons Attribution - Pas d'Utilisation Commerciale 4.0 International. 


\title{
In memoriam Jean-Jacques Tschudin
}

\author{
Claire-Akiko BRISSET \\ université Paris Diderot
}

« Rose, ô pure contradiction, volupté de n'être le sommeil de personne sous tant de paupières. $\gg^{1}$

Dans le journal du père de Jean-Jacques Tschudin (1934-2013), à la première entrée, datée du 2 décembre 1936, on peut lire : «Petit Jean-Jacques à deux ans, il trottine gaiement et avec célérité autour des tables, il veut "couir". »

Il voulait « couir » donc, et n'a pas tardé à faire le tour du monde en voyageur léger, jusqu’à ce Japon qui était déjà là dès sa première exposition de peinture à 25 ans. Dans la Feuille d'Avis de la Béroche de St-Aubin, entre la Chronique sportive et la Chronique neuchâteloise, un journaliste évoque en janvier 1961 une exposition de Jean-Jacques Tschudin à Peseux, une « exposition extravagante hors des chemins battus », faite pour « ceux qui ont besoin de passer les frontières étroites, les murs de notre horizon neuchâtelois; allez-y voir !». Il ne croyait pas si bien dire, cet éloquent chroniqueur. Sur la même page du journal, un long article était également consacré au Nouvel An japonais par le poète Philippe Jaccottet, grand amateur de haïku. Heureuse rencontre, à croire qu' il y avait quelque prédestination à ce départ.

1. Épitaphe présente sur la tombe de Rainer Maria Rilke et rédigée par lui. 
20 Cahiers d'études japonaises $n^{\circ} 21$

« Hors des chemins battus », le peintre Jean-Jacques ira donc au Japon, après l'Espagne, le Portugal, l'Italie, les États-Unis, le Canada, le Mexique, ou encore Cuba, selon un itinéraire folâtre, en ligne courbe, où les recherches picturales, le cinéma, les expérimentations avant-gardistes et déjà le spectacle joueront un grand rôle. Engagé très tard dans un cursus universitaire - une crise de la quarantaine bien à lui - il arrive un jour à Paris, où il est resté.

Assistant associé en 1981, puis maître-assistant, maître de conférences et enfin professeur à l'université Paris 7 (devenue depuis Paris Diderot), il y prendra sa retraite en 2003. C'est là que je l'ai connu et que j'ai pu profiter de sa mystérieuse et riche présence. D'aucuns étaient frappés par son « nihilisme » et son ironie : je n'y ai jamais vu que le masque élégant d'un homme plein de retenue, et qui n'a eu de cesse, comme enseignant, de transmettre avec sincérité et rigueur tout ce qu'il aimait. Curieusement pour un chercheur qui a consacré aux arts de la scène japonais ${ }^{2}$ l'essentiel de son œuvre, il n'a jamais souhaité assurer un cours sur son domaine de spécialité. Sans doute était-ce par pudeur, car s'il se méfiait de toutes les formes de complaisance, il a travaillé jusqu'à ses tout derniers jours à un livre qu'il savait alors posthume : L'Éblouissement d'un regard: découverte et réception occidentale du théatre japonais de la fin du Moyen âge à la Seconde Guerre mondiale $(2014)^{3}$. Un livre précieux dans lequel il rejoue, sur un mode distancié, sa propre rencontre éblouie avec le Japon et son théâtre, façon également de boucler la boucle et de revenir, en quelque sorte, au point de départ de son « grand voyage ».

Il est heureux que ce numéro de la revue Cipango consacré au théâtre japonais soit associé à la mémoire de Jean-Jacques Tschudin, amateur d'étude, de Shakespeare, de Rilke, de peinture et de Charles M. Schulz.

2. Citons La Ligue du théâtre prolétarien japonais (1989), Le Kabuki devant la modernité (1995), Histoire du théâtre classique japonais (2011), entre autres.

3. Compte rendu de lecture dans le présent numéro par Odette Aslan. 